\title{
$\mathfrak{b} \mathfrak{o} \mathfrak{r} \mathfrak{w} \mathfrak{c} \mathfrak{t}$
}

月on ben Entideibungen bes Reidjągeriđjts enthalten viele

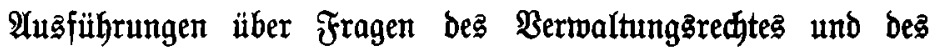
Bofizeiftrafredtez, und bürfte eine befondere überfichtlidue $z^{\mathfrak{u}=}$ fammenjtelluttg ber auf biefe Materien fid bejiegenden reidga geridjtliden $\mathfrak{A}$ (uspprüd)e, welde fid) in ben veridiebenen cibil= uno ftrafredtlidjen Sammlungen zerftreut vorfinben, atuen, welde auf gebachten Bebieten zu wirfen berufen find, nidtt mur geredt= fertigt, fonbern audy erwünidit erideinen.

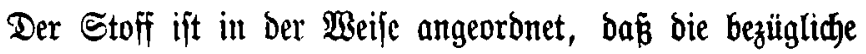

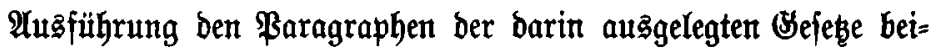
gefügt und bie Bejete felbft in dronologifder ßeihenfolge an=

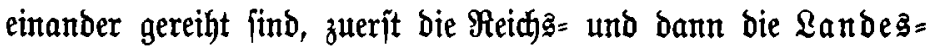
geiete.

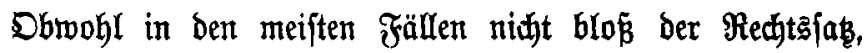
weldfer ausgefproden wurbe, fondern aud bie wejentlide $B_{e}=$ gründung unter Bermeifung auf bie babei benubte @ammlung mitgeteilt werben, fo wirb es immerhin für eine ridtige $\mathfrak{A}$ (ñwen= bung bes Mitgeteilten auf forgfältige Bürbigung ber thatfäd = lidjen $\mathfrak{u m}$ itäntbe bes einzelnen Falles anfommen und baher im

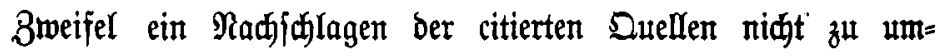
gethen fein. 


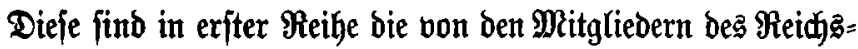

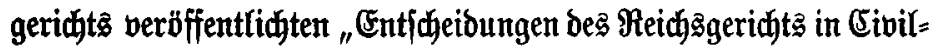
unb Straffachen", auf melde fich als "Entfd. in Sivilf." ober "Entfi. in Straff." bezogen wird, Dann bie bon Den Mitgliebern

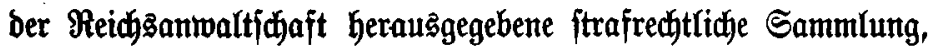

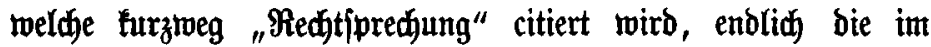
Beilagehefte zu Srutujot's Beiträgen, britte Folge, Jahrgang 1880 , enthaltenen Entiafeidungen.

Bo bie Iusfühhrungen aus ben genannten Quellen wörtlid)

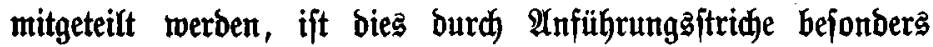
fermtlid gemacht.

B̧rimma, im März 1883.

\section{Det Şerauģgeber.}

